\title{
SHOULD REMISSION OF TYPE 2 DIABETES MELLITUS BE THE FOREMOST GOAL AFTER BARIATRIC SURGERY?
}

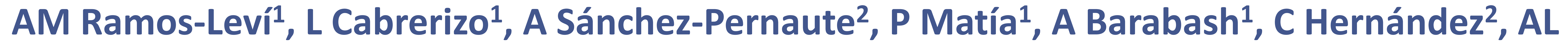 \\ Calle-Pascual ${ }^{1}$, AJ Torres García², MA Rubio \\ ${ }^{1}$ Department of Endocrinology and Nutrition, ${ }^{2}$ Department of Surgery. Hospital Clínico San Carlos, IdISSC. Madrid.
}

\section{INTRODUCTION}

Remission of type 2 diabetes (T2D) is a yearned outcome after bariatric surgery (BS). Attention to individuals who do not strictly fulfill remission criteria has been frequently left behind. The aim of this study was to evaluate metabolic control status in patients considered as diabetes "non-remitters".

\section{PATIENTS AND METHODS}

Retrospective study of 125 patients (59.2\% women) with preoperative diagnosis of T2D who underwent BS in a single center (2006-2011). Anthropometric and metabolic parameters, before surgery and at one-year follow-up

Definition of $T 2 D$ remission according to Buse et al: $H b A 1 c<6 \%$, fasting glucose $(F G)<100 \mathrm{mg} / \mathrm{dL}$, absence of pharmacologic treatment. Evaluation of metabolic status of non-remitters, according to ADA's target recommendations of glucose and lipid control: HbA1c < 7\%, LDL-c < 100 $\mathrm{mg} / \mathrm{dL}$, triglycerides $<150 \mathrm{mg} / \mathrm{dL}, \mathrm{HDL}-\mathrm{c}>40$ (male) or $>50 \mathrm{mg} / \mathrm{dL}$ (female). Statistics: analysis of variance.

\section{RESULTS}

Preoperatively (mean \pm SD): age $53.5 \pm 9.7$ years, BMI $43.5 \pm 5.6 \mathrm{~kg} / \mathrm{m} 2$, duration of T2D $7.7 \pm 7.9$ years, FG $162.0 \pm 56.3 \mathrm{mg} / \mathrm{dl}, \mathrm{HbA} 1 \mathrm{c} 7.7 \pm 1.6 \%$, LDL-c $100.9 \pm 29.1 \mathrm{mg} / \mathrm{dL}$, HDL-c $48.6 \pm 12.3 \mathrm{mg} / \mathrm{dL}$, triglycerides (Tg) 195.7 $\pm 128.7 \mathrm{mg} / \mathrm{dL}$. $43.2 \%$ had previous insulin treatment, $38.4 \%$ had $\mathrm{HbA} 1 \mathrm{c}<$ $7 \%$ and only $9.6 \%$ (12 patients) fulfilled ADA's target recommendations regarding optimal combined metabolic control.

At one year follow-up, 62 (49.6\%) patients did not achieve diabetes remission as defined by Buse et al (figure 1a); rates were different according to previous hypoglycemic treatment (figure 1b). Table 1 shows patients' baseline and 12-months' follow-up characteristics according to their T2D remission status. Hypoglycemic treatment according to remission status is shown in table 2.

Of the non-remitters, $91.9 \%$ had $\mathrm{HbA} 1 \mathrm{c}<7 \%$ (figure 2 ) and $40.0 \%$ achieved ADA's target recommendations (figure 3). There were no differences between remitters and non-remitters in the number of individuals reaching ADA's target glucose and lipid levels.

\begin{tabular}{lcccc} 
& \multicolumn{2}{c}{ Remission } & \multicolumn{2}{c}{ No remission } \\
\cline { 2 - 5 } & Preop & $12-m$ & Preop & $12-m$ \\
No / Diet & 0 & 0 & 0 & 41.9 \\
Oral agents & 73.0 & 0 & 40.3 & 48.4 \\
Insulin & 27.0 & 0 & 59.7 & 9.7 \\
\hline
\end{tabular}

Table 2. Preoperative ("preop") and 12month $(12 \mathrm{~m})$ follow-up hypoglycemic treatment, according to remission status. Percentage of patients

\section{CONCLUSIONS}

